\title{
Superconducting strand and cable development for the LHC upgrades and beyond
}

\author{
E. Barzi, N. Andreev, G. Apollinari, F. Bucciarelli, V. Lombardo, F. Nobrega, D. Turrioni, R. Yamada, \\ and A.V. Zlobin
}

\begin{abstract}
Fermilab and CERN [1] have started the development of $11 \mathrm{~T} \mathrm{Nb}_{3} \mathrm{Sn}$ dipoles to replace a number of $\mathrm{LHC}$ $\mathrm{NbTi}$ dipole magnets and free space for the additional collimators anticipated for the LHC luminosity upgrades. An essential step in the design of these magnets is the development of the 40-strand, high aspect ratio cable needed to achieve the nominal field of $11 \mathrm{~T}$ at the LHC operating current of $11.85 \mathrm{kA}[2,3]$. To investigate conductors suited for this and other high field magnet applications, a larger Superconducting Strand and Cable R\&D lab was established at FNAL's Technical Division. Keystoned cables with and without a stainless steel core were developed and produced using $0.7 \mathrm{~mm} \mathrm{Nb}_{3} \mathrm{Sn}$ strands made by Oxford Superconducting Technology with 127 (baseline) and 169 (advanced) restacks using the Restacked-Rod-Process ${ }^{\circledR}$. The electrical performance of these two strands is compared in cables made with different processes and geometries. Some of the effects of a cross-over in the cable were measured. Finally, it is shown how finite element modeling can be used as an aid in Rutherfordtype cable design.
\end{abstract}

Index Terms-Accelerator magnet, $\mathrm{Nb}_{3} \mathrm{Sn}$ wires, Rutherford cable, subelement.

\section{INTRODUCTION}

$\mathrm{P}$ ROGRESS in $\mathrm{Nb}_{3} \mathrm{Sn}$ accelerator magnet technology by USLARP $[4,5]$ and core programs in U.S. National Laboratories $[6,7]$ and elsewhere $[8,9]$ makes it possible to envision $\mathrm{Nb}_{3} \mathrm{Sn}$ magnets with nominal fields up to $12 \mathrm{~T}$ in actual machines, particularly for the LHC luminosity upgrades. For the LHC collimation system upgrade, which will enable beam operation at nominal and ultimate intensities, Fermilab and CERN have started the development of $11 \mathrm{~T}$ $\mathrm{Nb}_{3} \mathrm{Sn}$ dipoles $11 \mathrm{~m}$ long to replace a number of $8.33 \mathrm{~T} \mathrm{NbTi}$ main dipoles $15 \mathrm{~m}$ long and free space for additional cryocollimators that are anticipated in the LHC dispersion suppression (DS) regions [8]. These twin-aperture dipoles operating at $1.9 \mathrm{~K}$ will be powered in series with the main dipoles and deliver the same integrated strength of $119 \mathrm{Tm}$ at the LHC nominal operating current of $11.85 \mathrm{kA}$ [10].

An important step in the design of these magnets is the development of the high aspect ratio $\mathrm{Nb}_{3}$ Sn Rutherford-type cable that is needed to achieve the nominal field of $11 \mathrm{~T}$ with

Manuscript received October 9, 2012. This work was supported in part by Fermi Research Alliance, LLC, under Contract DE-AC02-07CH11359 with the US Department of Energy.

E. Barzi, G. Apollinari, V. Lombardo, F. Nobrega, D. Turrioni, R. Yamada and A.V. Zlobin are with Fermilab National Accelerator Laboratory, Batavia, IL 60510, USA (e-mail: barzi@ fnal.gov).

F. Bucciarelli is with the Scuola Superiore Sant'Anna, 56127 Pisa, Italy.
$20 \%$ margin. The wire to be used in the FNAL short models of the $11 \mathrm{~T}$ demonstrator dipole is made with the Restacked-Rod Process (RRP®) by Oxford Superconducting Technology (OST), has 108 superconducting (SC) bundles within a layout of 127 restacks, and extra $\mathrm{Cu}$ between the superconducting elements [11]. With a geometrical subelement size of $41 \mu \mathrm{m}$, a good critical current density, $J_{c}$, and long length production, it was shown in strand studies $[12,13]$ and also proven in magnets $[4,6]$ that this strand withstands the cabling process, producing stable magnet behavior down to $1.9 \mathrm{~K}$. This wire is presently a baseline conductor for $\mathrm{Nb}_{3} \mathrm{Sn}$ magnet $\mathrm{R} \& \mathrm{D}$ in the U.S. However, it is clear that at the LHC operation temperature of $1.9 \mathrm{~K}$, at which the conductor exhibits a much larger $J_{c}$, these strands still operate on the verge of electromagnetic instability, and that further reducing the superconducting subelement size would also improve magnetic field quality. Therefore, a more advanced RRP® strand with 150 SC bundles within a layout of 169 restacks that had been developed with OST [13] was also used in cabling studies and its behavior in cables compared with that of the baseline wire. The present study compares the effect of increasing compaction of keystoned Rutherford-type cables with and without a stainless steel core, and with and without an intermediate annealing process between the two cable fabrication steps. The two wires are also compared when used as witness samples of the magnet heat treatment process.

Another important aspect for long length production of cable for magnet prototypes is cable quality control. Optical inspection systems can be installed in the cabling line for a continuous inspection of the cable to detect defects like crossovers and stop cable production [14]. However, since presently cross-overs are not accepted in cables to be used for magnet manufacture, and because of the larger costs of $\mathrm{Nb}_{3} \mathrm{Sn}$ compared to $\mathrm{NbTi}$, it is natural to inquire whether cross-overs could be tolerated in magnets after all. To help answer this question, a study was performed to measure some of the effects of a cross-over in the cable.

Finally, it is shown how an upgraded ANSYS finite element model can be used as an aid in cable design.

\section{INFRASTRUCTURE}

\section{A. Cabling Facility}

The Cabling Facility, located in Industrial Building 3 (IB3) of FNAL's Technical Division, includes a compact cabling machine with 42 spools and electronic synchronization for lay angle control, a re-spooler, sets of forming fixtures, mandrels 
and measuring devices [15]. The cabling machine is shown in Fig. 1. Operations include re-spooling of strands, transposition of strands into a cable and forming of the cable with a round, rectangular or keystoned cross section, control of the cross section size, and cable spooling onto the pick-up reel. Cable quality control includes measurements of the strand diameter, visual inspection of the cable during fabrication to check for cross-overs and other possible imperfections, measurements of cable thickness and width, microstructural analysis of cable cross sections, and electrical characterization of both virgin and extracted strands. Production speed is $\sim 1 \mathrm{~m} / \mathrm{min}$. Rectangular cables can be fabricated from 5 to $17.75 \mathrm{~mm}$ in width. Cables have been fabricated with and without stainless steel core, out of both conventional conductors like $\mathrm{Cu}$ and $\mathrm{Ag}$, and superconducting round wires, including $\mathrm{NbTi}, \mathrm{Nb}_{3} \mathrm{Sn}$, $\mathrm{Nb}_{3} \mathrm{Al}$, and $\mathrm{Bi}-2212[15,16,17]$.

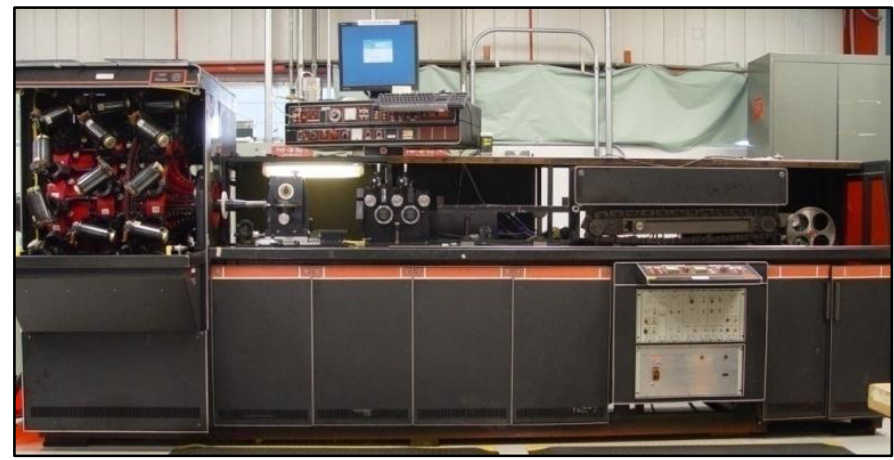

Fig. 1. FNAL compact cabling machine with 42 spools and electronic synchronization for control of cable lay angle.

The cables in the present study were made using a twostage cable fabrication (Fig. 2). First a rectangular cable with narrower width and lower compaction is manufactured, then the rectangular cable is re-rolled to produce a keystoned cable with final cross section. The rectangular cables were made with a forming fixture composed of two vertical rolls $\sim 20 \mathrm{~mm}$ wide and two horizontal rolls $1.2 \mathrm{~mm}$ thick, both with variable gaps. The keystoned cables were made using a two-roll die with variable gap, and with fixed keystone angle and cable width [15]. In preparation to $11 \mathrm{~T}$ dipole coil scale up to $5.5 \mathrm{~m}$ long, a new turk-head designed for one-pass cable fabrication was tested and commissioned (Fig. 3).

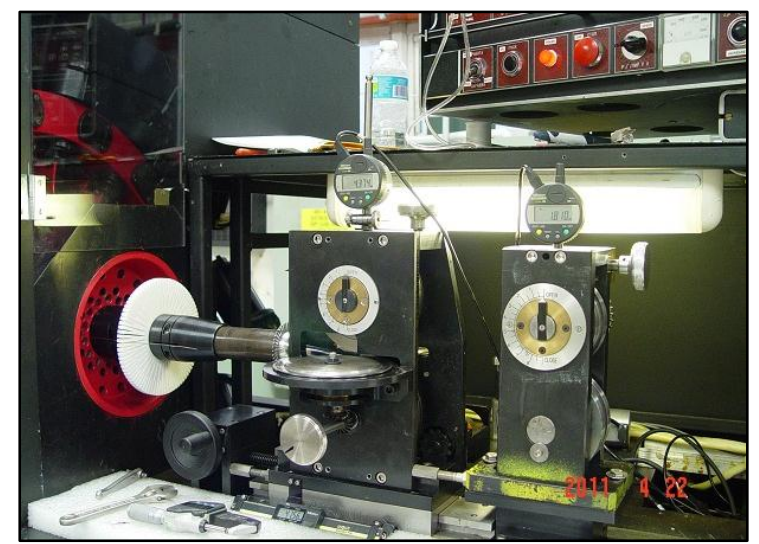

Fig. 2. Forming fixture and keystoning rollers for two-stage cable fabrication.

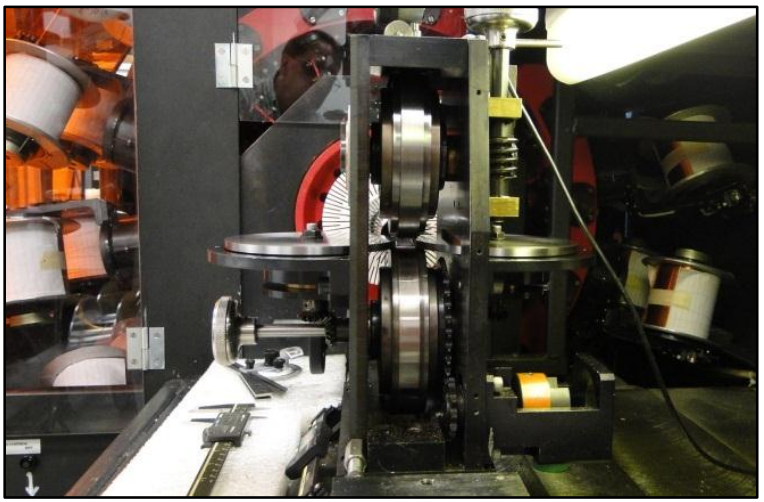

Fig. 3. Turk-head for one-pass cable fabrication.

\section{B. Superconducting Strand and Cable $R \& D$ Lab}

To investigate conductors suited for high field magnet applications, a larger Superconducting Strand and Cable R\&D lab was established in a $~ 6000$ square feet addition to IB3 at FNAL's Technical Division (Fig. 4). Such new building, which was constructed in 2010 with ARRA funds, includes the following cryogenic equipment:

- Teslatron 1, a 15T/17T magnetic cryostat by Oxford Instruments with $64 \mathrm{~mm}$ cold aperture and a Variable Temperature Inserts (VTI) for measurements between $1.5 \mathrm{~K}$ and $300 \mathrm{~K}$ (see schematic in Fig. 6). Master and slave power supplies provide $1875 \mathrm{~A}$. The DAQ includes current, voltage, temperature, magnetic field and helium level readings, as well as quench protection.

- Teslatron 2, a 14T/16T magnetic cryostat by Oxford Instruments with $77 \mathrm{~mm}$ cold aperture and a VTI for measurements between $1.5 \mathrm{~K}$ and $300 \mathrm{~K}$. Master and slave power supplies provide $2000 \mathrm{~A}$. In addition to the same readings as above, the DAQ for this system also includes an integrator for magnetization measurements and for high current measurements through a Rogowski coil.

- Teslatron 3, a vacuum insulated liquid helium dewar of $\sim 50$ liters with a neck of $253 \mathrm{~mm}$. The power supply provides $2400 \mathrm{~A}$. The DAQ includes current, voltage, temperature, magnetic field and helium level readings, as well as quench protection. This cryostat can be used to test stand-alone coils with maximum OD of $252 \mathrm{~mm}$, and was used to test HTS helical coils.

- Teslatron 4, an 8.5T/10T magnetic cryostat by Oxford Instruments with $147 \mathrm{~mm}$ cold aperture. The power supply provides $2400 \mathrm{~A}$. The DAQ includes current, voltage, temperature, magnetic field and helium level readings, as well as quench protection. This system is in the process of being commissioned. Can be used in the future to test HTS solenoids up to $146 \mathrm{~mm}$ in OD up to $10 \mathrm{~T}$ field, and/or cables.

- A low temperature cell loader for strain gauge calibration both at room temperature and at $4.2 \mathrm{~K}$.

The four Teslatron systems are shown along their vent and vacuum lines in Fig. 5. A schematic of a typical magnet, cryostat and VTI assembly is shown in Fig. 6.

The Lab also includes the following equipment:

- Four tube furnaces of $\sim 6$ inches diameter and at least 12 
inches homogeneity volume for heat treatment of superconductors in argon and oxygen up to $1500^{\circ} \mathrm{C}$.

- A $2 \mathrm{~m}$ long furnace for heat treatment in air and in argon up to $1250^{\circ} \mathrm{C}$.

- A metrology well calibrator for accurate ovens' thermocouple calibration up to $700^{\circ} \mathrm{C}$.

- A motorized flat-rolling system to impart plastic strain within a desired range to round superconducting wires, usually before heat treatment, for superconductor studies [18, 19]. The strand is flattened vertically, and it is free to expand laterally. Wire deformation is defined as $(d-t) / d$, where $d$ is the original strand diameter and $t$ is the thickness of the deformed strand.

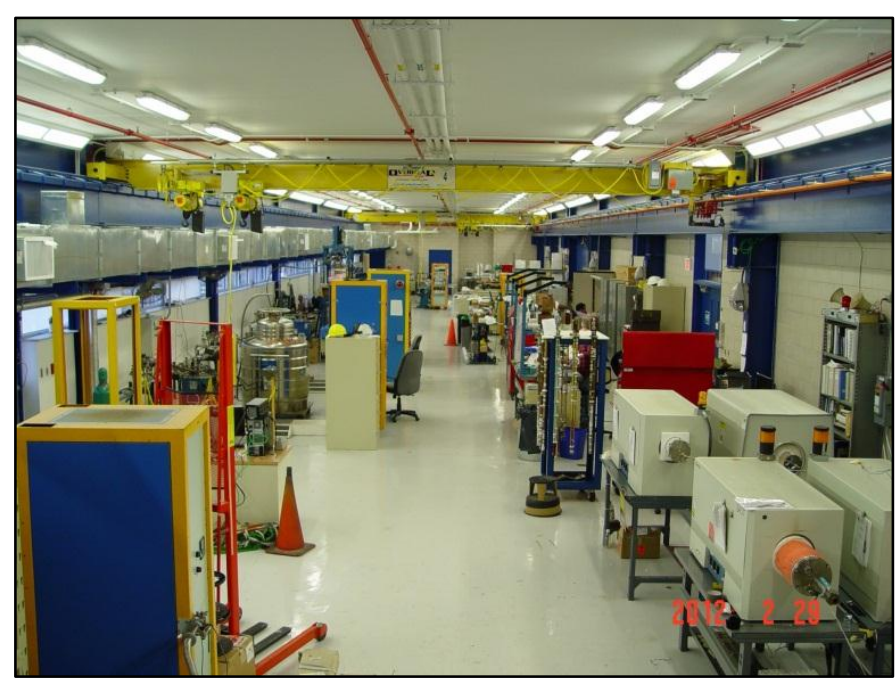

Fig. 4. New Superconducting Strand and Cable R\&D Lab, as established in a 6000 square feet addition to Industrial Building 3 at FNAL's Technical Division.

The experimental setups that were designed to operate within the equipment above in order to perform superconductor research since 1998 include:

- Probes and sample holders for superconducting strand stable tests using ITER-type barrels in liquid Helium up to $15 \mathrm{~T} / 17 \mathrm{~T}$ at currents up to $1400 \mathrm{~A}$. Can operate both in Teslatron 1 and Teslatron 2.

- Five low resistance probes and samples holders, which also use ITER-type barrels, but are capable of reaching stable currents up to $2000 \mathrm{~A}$ at temperatures between $1.9 \mathrm{~K}$ and 4.5 K. Can operate both in Teslatron 1 and Teslatron 2.

- Sample holders to measure critical current of HTS wires, and sample holder to measure the angular dependence of current with respect to magnetic field up to $15 \mathrm{~T}$ and at temperatures between $1.5 \mathrm{~K}$ to $60 \mathrm{~K}$. Can operate both in Teslatron 1 and Teslatron 2 [20, 21].

- A balanced coil magnetometer to measure magnetization of conventional (iron) and superconducting materials (bulk $\mathrm{Nb}, \mathrm{Nb}$ based multifilamentary superconductors, etc.) between 0 and $15 \mathrm{~T}$ and at temperatures between $1.5 \mathrm{~K}$ to $300 \mathrm{~K}$ for operation in Teslatron 2. Samples are wound on stainless steel tubes for heat treatment. They are then transferred onto G-10 holders for testing. Magnetization is measured using a balanced coil magnetometer with a typical magnetic field ramp rate of $17 \mathrm{mT} / \mathrm{s}$.

- A device to test critical current sensitivity of impregnated superconducting cables to uniaxial (plane stress) transverse pressures up to $200 \mathrm{MPa}$, and sample impregnation fixtures. Operates both in Teslatron 1 and Teslatron 2 [22].

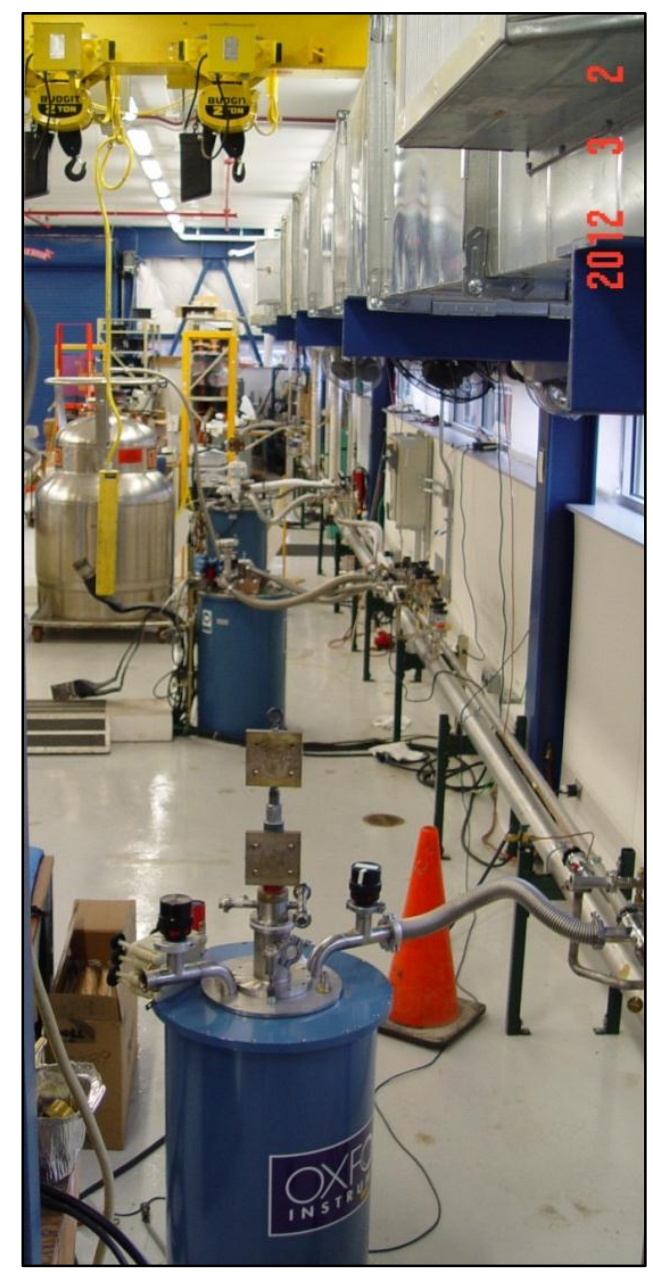

Fig. 5. Four cryostats with up to $15 \mathrm{~T} / 17 \mathrm{~T}$ background field, and with cold apertures between $64 \mathrm{~mm}$ and $147 \mathrm{~mm}$ are connected to new vent and vacuum systems.

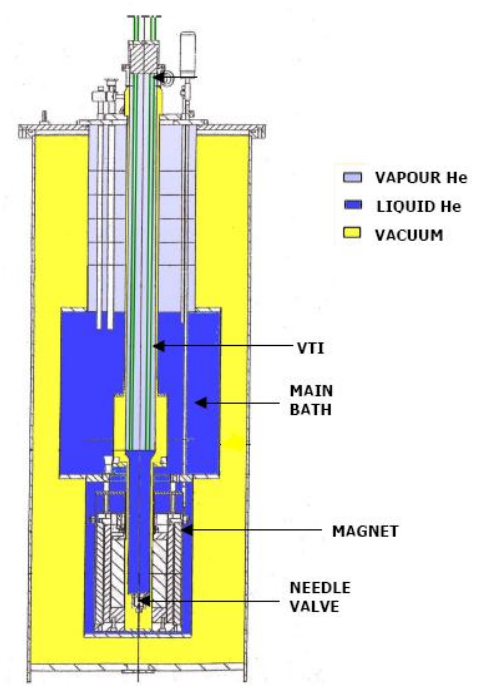

Fig. 6. Schematic of a typical magnet, cryostat and VTI assembly. 
- A Walters' spring-type device for tensile/compressive strain sensitivity studies of $J_{c}$ in superconducting wires for operation in Teslatron 1 [23]. This probe, shown in Fig. 9 (left), is in the process of being calibrated and commissioned.

- Superconducting transformer for Rutherford cable tests at self-field up to $28 \mathrm{kA}$ [24]. Also used in splice studies [25]. Operates in Teslatron 2.

- A 14T/16T Rutherford cable test facility with bi-filar sample and superconducting transformer (Fig. 9, right) operating in Teslatron 2 [26]. Upgrades to the sample holder and support tube are being tested and commissioned to increase cable current above the present limit of $11 \mathrm{kA}$.

- A modular Insert Test Facility (ITF) to test double pancake coils made of YBCO in Teslatron 2 [27]. Single double pancake units, and a four double pancake coil that produced a maximum field on the conductor of $21.5 \mathrm{~T}$ were tested with the modular ITF up to $14 \mathrm{~T}$ in Teslatron 2 [28].

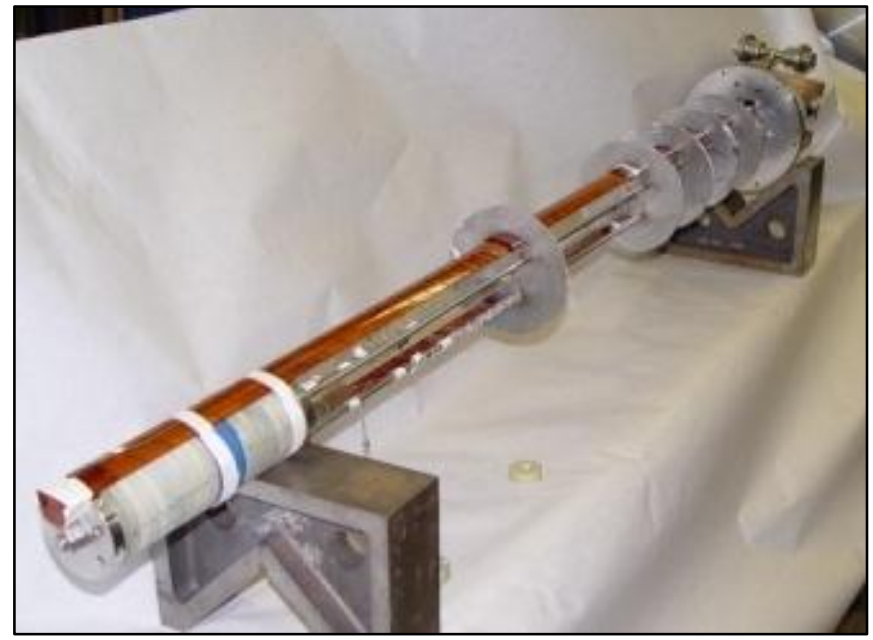

Fig. 7. Modular Insert Test Facility (ITF) designed to test double pancake coils made of YBCO in Teslatron 2 [27].

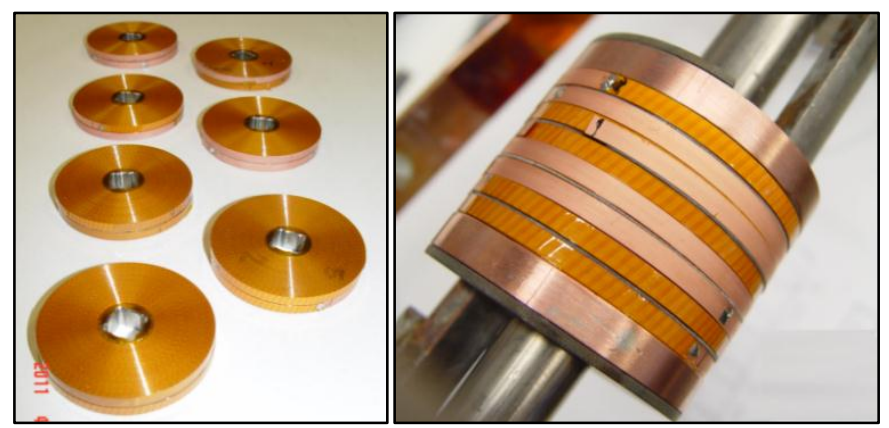

Fig. 8. Double pancake coil units made of YBCO (left), and a four double pancake coil that produced a maximum field on the conductor of $21.5 \mathrm{~T}$ when tested with the modular ITF of Fig. 7 in Teslatron 2 [28] (right).

Since 1998, the Superconducting Strand and Cable R\&D Lab has served as ideal experimental environment for 30 graduate students in Physics and Engineering to receive hands-on training in superconductivity, strain theory, heat transfer, cryogenics, mechanical design, electronics, computing and automation during Summer internships or Specialized Laurea or $\mathrm{PhD}$ theses.
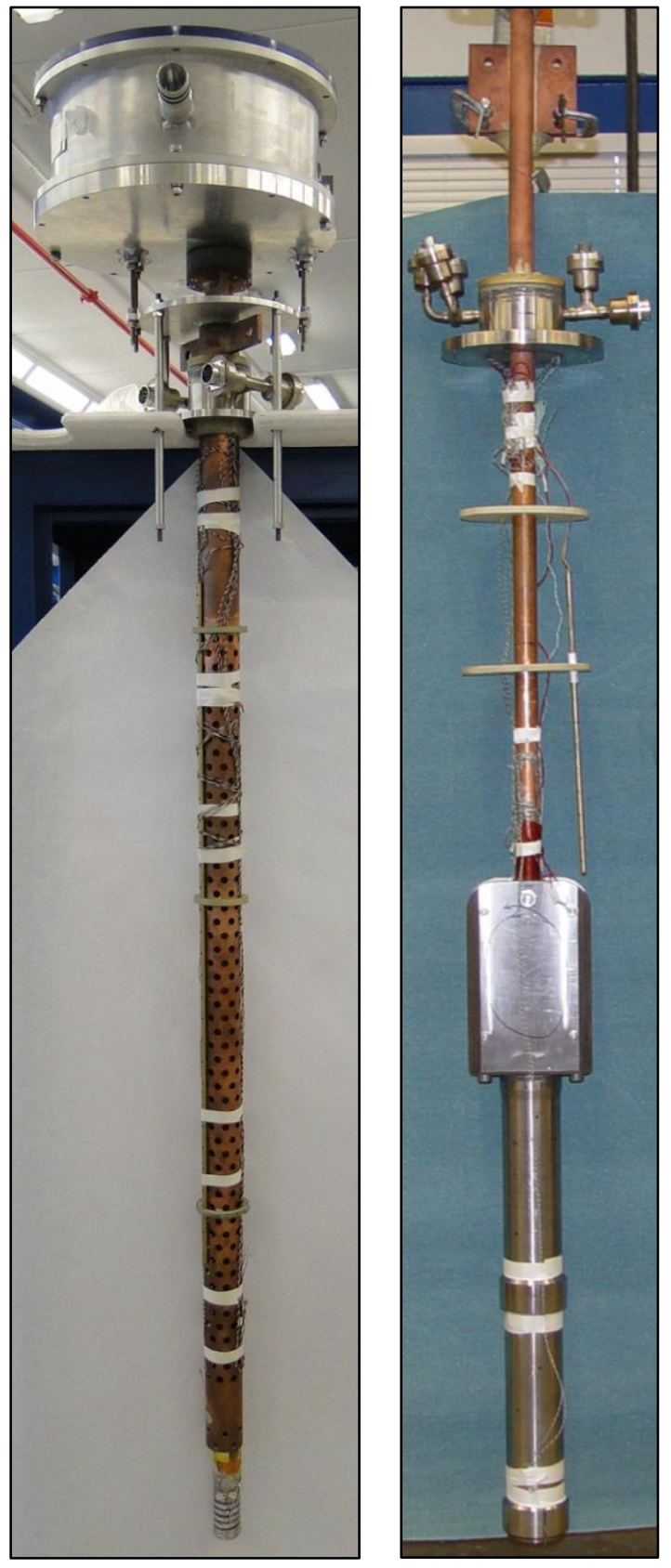

Fig. 9. Walters' spring-type device for tensile/compressive strain sensitivity measurements of $J_{c}$ in superconducting wires [24] (left), and superconducting transformer with bi-filar sample for cable tests in field up to $14 \mathrm{~T} / 16 \mathrm{~T}$ and 11 kA [26] (right).

\section{STRAND AND CABLE DESCRIPTION}

\section{A. Strand Description}

Table I shows parameters of the 150/169 RRP® (RRP1) and the 108/127 RRP® (RRP2) strands. Pictures of the cross sections are in Fig. 10. When using their respective nominal heat treatment, i.e. as optimized for magnet reaction, the RRP1 strand produced a $J_{c}(4.2 \mathrm{~K}, 12 \mathrm{~T})$ of $2650 \mathrm{~A} / \mathrm{mm}^{2}$, and the RRP2 wire a $J_{c}(4.2 \mathrm{~K}, 12 \mathrm{~T})$ of $2460 \mathrm{~A} / \mathrm{mm}^{2}$. In Table, $D_{S}$ is the geometrical subelement size of the flat to flat dimension of the hexagonal outer diffusion barrier, as calculated from design, unreacted. 
TABLE I STRAND PARAMETERS

\begin{tabular}{lcc}
\hline \hline Strand ID & RRP1 & RRP2 \\
\hline Stack design & $150 / 169$ & $108 / 127$ \\
Strand diameters $d, \mathrm{~mm}^{2}$ & 0.7 & 0.7 \\
$J_{c}(4.2 \mathrm{~K}, 12 \mathrm{~T}), \mathrm{A} / \mathrm{mm}^{2}$ & 2,650 & $2,460-2,890$ \\
$D_{S}, \mu \mathrm{m}$ & 36 & 41 \\
Twist pitch, $\mathrm{mm}$ & 13 & 14 \\
Cu fraction, $\%$ & 51.8 & 55.5 \\
\hline \hline
\end{tabular}

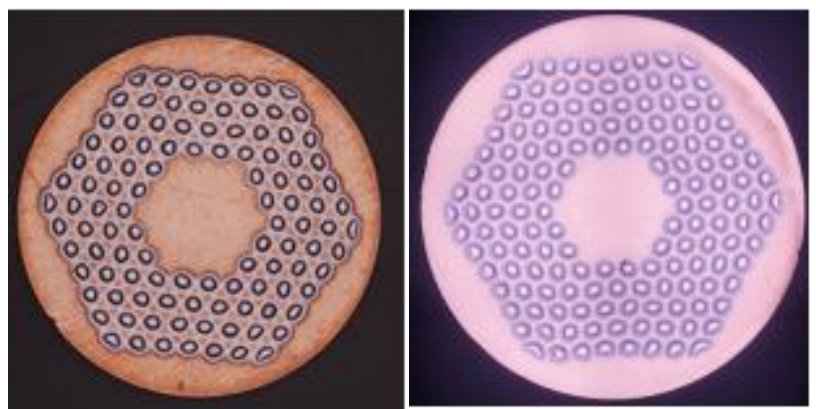

Fig. 10. 108/127 (left), and 150/169 (right) RRP® designs used in this study.

\section{B. Cable Description}

The factors used in selecting the cable geometry at the start of the $11 \mathrm{~T}$ dipole program were the following. The goal of producing nominal cable both at CERN and at FNAL imposed a limit of 40 on the maximum number of strands. A $0.7 \mathrm{~mm}$ for the strand diameter was dictated by the required magnet transfer function of at least $11 \mathrm{~T}$ at $11.85 \mathrm{kA}$. The deformation of the small edge, defined as $1-t_{\text {thin edge }} / 2 d$, had to be less than $20 \%$, whereas width compaction $w_{c}$, defined as $w_{i d t h}$ cable $w_{i d t h} h_{\text {undeformed }}$ had to be larger than 1 . And finally, the critical current degradation due to cabling was requested to be less than $10 \%$ to provide the required $20 \%$ operation margin. The cable R\&D preliminary to magnet design was performed for cables $15.1 \mathrm{~mm}$ and $14.7 \mathrm{~mm}$ wide. It was found that cables $15.1 \mathrm{~mm}$ wide required 41 strands to be fabricated in a mechanically stable form, therefore $14.7 \mathrm{~mm}$ was chosen as the dipole bare coil layer width. Aiming at an $86 \%$ cable compaction, a cable mid-thickness of $1.27 \mathrm{~mm}$ was then selected [2]. Sensitivity studies to cable compaction that were performed post-magnet design using the baseline wire showed that reducing the uncored keystoned cable thickness from $1.27 \mathrm{~mm}$ to $1.25 \mathrm{~mm}$ improved the cable mechanical stability while preserving the degradation of the critical current, $I_{c}$, within specifications. Table II summarizes the latest cable specifications (v.2) for the $11 \mathrm{~T}$ dipole program [3].

TABLE II UNREACTED CABLE SPECIFICATIONS

\begin{tabular}{lc}
\hline Parameter & Value \\
\hline Cable unit length $(\mathrm{m})$ & 210,620 \\
Number of strands & 40 \\
Transposition angle (degrees) & 15 \\
Mid-thickness (mm) & 1.250 \\
Thin edge (mm) & 1.149 \\
Thick edge (mm) & 1.351 \\
Width (mm) & 14.70 \\
Keystone angle (degrees) & 0.79 \\
Insulation thickness (mm) & 150 \\
\hline
\end{tabular}

A number of cable development studies were performed since establishing the specifications for the uncored cable to be fabricated with the baseline strand. The first of these studies was the development of a cored cable technology to suppress eddy currents $[29,30]$ and obtain better field quality and ramp rate dependence. Such study was first performed using the advanced strand 150/169 RRP ${ }^{\circledR}$ and a stainless steel core $11 \mathrm{~mm}$ wide and $25 \mu \mathrm{m}$ thick, and it was carried out for cable samples that had undergone an intermediate annealing process between their first forming stage and their keystoning step, and for cable samples that had not undergone such process. To study sensitivity of electrical properties and damage to compaction, the cored cables were made within a range of mid-thicknesses producing Packing Factors, $P F$, between $\sim 85 \%$ and $\sim 90 \%$. The cored technology was then applied to the baseline 108/127 RRP® wire using a stainless steel core $11.7 \mathrm{~mm}$ wide and $25 \mu \mathrm{m}$ thick. Table III summarizes the parameters of this set of keystoned cables, which includes cables ID's 2 to 10 . The cross section of one of these cables is shown in Fig. 11. The rectangular cable ID 1 was used to study cross-over effects.

\begin{tabular}{cccccc}
\multicolumn{6}{c}{ TABLE III CABLES FOR DEVELOPMENT OF CORED CABLE TECHNOLOGY } \\
\hline $\begin{array}{c}\text { Cable } \\
\text { ID }\end{array}$ & $\begin{array}{c}\text { RRP® } \\
\text { wire } \\
\text { design }\end{array}$ & $\begin{array}{c}\text { Width } \\
\text { before/after } \\
\text { keystoning } \\
\text { (mm) }\end{array}$ & $\begin{array}{c}\text { Mid-thickness } \\
\text { before/after } \\
\text { keystoning (mm) }\end{array}$ & PF(\%) & $\begin{array}{c}\text { Annealing } \\
\text { step }\end{array}$ \\
\hline 1 & $150 / 169$ & $14.50 /-$ & $1.307 /-$ & $85.2 /-$ & No \\
2 & $150 / 169$ & $14.48 / 14.66$ & $1.320 / 1.270$ & $84.8 / 87.1$ & No \\
3 & $150 / 169$ & $14.48 / 14.66$ & $1.320 / 1.253$ & $84.8 / 88.3$ & No \\
4 & $150 / 169$ & $14.48 / 14.68$ & $1.320 / 1.230$ & $84.8 / 89.8$ & No \\
5 & $150 / 169$ & $14.57 / 14.68$ & $1.338 / 1.270$ & $83.4 / 86.8$ & Yes \\
6 & $150 / 169$ & $14.57 / 14.68$ & $1.338 / 1.251$ & $83.4 / 88.4$ & Yes \\
7 & $150 / 169$ & $14.57 / 14.69$ & $1.338 / 1.232$ & $83.4 / 89.6$ & Yes \\
8 & $108 / 127$ & $14.59 / 14.70$ & $1.336 / 1.270$ & $83.0 / 86.7$ & Yes \\
9 & $108 / 127$ & $14.59 / 14.70$ & $1.336 / 1.252$ & $83.0 / 87.9$ & Yes \\
10 & $108 / 127$ & $14.59 / 14.71$ & $1.336 / 1.230$ & $83.0 / 89.4$ & Yes \\
\hline
\end{tabular}

All cables had a stainless steel core $0.25 \mu \mathrm{m}$ thick. The cables made with $150 / 169 \mathrm{RRP} \circledast$ wire were $11 \mathrm{~mm}$ wide, those made with $108 / 127 \mathrm{RRP} \circledast$ were $11.7 \mathrm{~mm}$ wide.

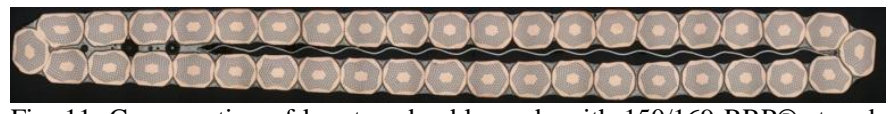

Fig. 11. Cross section of keystoned cable made with 150/169 RRP® strands and a stainless steel core $11 \mathrm{~mm}$ wide and $25 \mu \mathrm{m}$ thick.

\section{Sample Preparation and Measurement Procedure}

Round and extracted strand samples were wound on grooved cylindrical barrels made of Ti-alloy, and heat treated in Argon atmosphere. After reaction, the samples were tested on the same barrel. Stycast was used on the sample. The $I_{c}$ was determined from the voltage-current $(V-I)$ curve using the $10^{-14} \Omega \cdot \mathrm{m}$ resistivity criterion. Typical $I_{c}$ measurement uncertainties are within $\pm 1 \%$ at $4.2 \mathrm{~K}$ and $12 \mathrm{~T}$. The stability current, $I_{S}$, was obtained through $V-H$ tests as a local minimum of the quench current between 0 and $4 \mathrm{~T}$.

In standard strand $I_{c}$ measurements, 3 pairs of voltage taps were used. Two pairs were placed at the center of the sample $50 \mathrm{~cm}$ and $75 \mathrm{~cm}$ apart, and one pair at the $\mathrm{Cu}$ leads to be used for quench protection. When studying cross-over effects, in 
addition to the taps on the leads, 5 pairs of voltage taps were used, as shown in the schematic of Fig. 12. The voltage taps indicated as $\mathrm{CH} 1, \mathrm{CH} 2, \mathrm{CH} 3$, and $\mathrm{CH} 4$ in Fig. 12 were placed $1.5 \mathrm{~cm}$ apart to measure as accurately as possible the local $I_{c}$ in the damaged areas, as well as over edges that were not affected by the cross-over. The voltage tap indicated as $\mathrm{CH} 5$ represents the standard pair that is $75 \mathrm{~cm}$ apart.

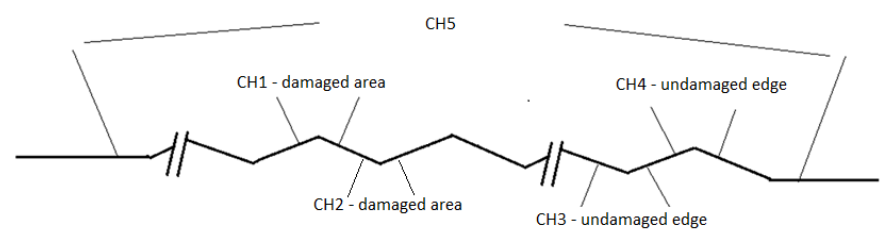

Fig. 12. Schematic of voltage taps used when studying cross-over effects.

\section{EXPERIMENTAL RESULTS AND DISCUSSION}

\section{A. Development of Cored Cable Technology}

Figs. 13 to 17 present the results of studies described in III. $B$ for cored cables identified in Table III. Unless otherwise specified, all the RRP1 round and extracted strands were given a heat treatment with dwells at $210^{\circ} \mathrm{C}$ for $48 \mathrm{~h}$, at $400^{\circ} \mathrm{C}$ for $48 \mathrm{~h}$ and at $665^{\circ} \mathrm{C}$ for $50 \mathrm{~h}$, and all the RRP2 round and extracted strands were given a heat treatment with dwells at $210^{\circ} \mathrm{C}$ for $48 \mathrm{~h}$, at $400^{\circ} \mathrm{C}$ for $48 \mathrm{~h}$ and at $640^{\circ} \mathrm{C}$ for $50 \mathrm{~h}$. In both cases, temperature ramp rates to reach the respective dwells were of $25^{\circ} \mathrm{C} / \mathrm{h}, 50^{\circ} \mathrm{C} / \mathrm{h}$ and $75^{\circ} \mathrm{C} / \mathrm{h}$.

Fig. 13 compares the $I_{c}(12 \mathrm{~T})$ of the extracted strand normalized to that of a round strand as function of cable midthickness between cables made with RRP1 strands that had undergone an intermediate annealing process between their first forming stage and their keystoning step, and cables that had not undergone such process. Whereas intermediate annealing appears to help preserve current carrying capabilities, cored cables of mid-thickness down to $\sim 1.25 \mathrm{~mm}$ perform in excess of the specifications of $10 \%$ maximum $I_{c}$ degradation.

Fig. 14 compares the Residual Resistivity Ratio (RRR) of the extracted strand as function of cable mid-thickness between cables made with RRP1 strands that had undergone an intermediate annealing process, and cables that had not undergone such process. For both cases, it is apparent that the RRP1 wire is capable of retaining an excellent $R R R$ for cable compaction factors of up to $\sim 90 \%$.

In Fig. 15, the $I_{c}(12 \mathrm{~T})$ of the extracted strand normalized to that of a round strand as function of cable mid-thickness is compared between cables made with RRP2 strands that had been made with a stainless steel core, and cables that had no core [3]. Both sets of cables, which all had undergone an intermediate annealing process, perform in excess of the specifications of $10 \%$ maximum $I_{c}$ degradation up to $\sim 90 \%$ compaction. The seemingly lower sensitivity to damage of the cored cables is possibly real, but needs to be confirmed with additional statistics. However, it is clear from these results that a mid-thickness specification for the cable of $1.25 \mathrm{~mm}$ meets the $I_{c}$ degradation requirements also in the case of a cored cable made with either RRP1 or RRP2 wire. Using the same cable geometry for cored and uncored cable allows preserving the same insulation thickness in the coil and keeping the same magnet design in the two cases.

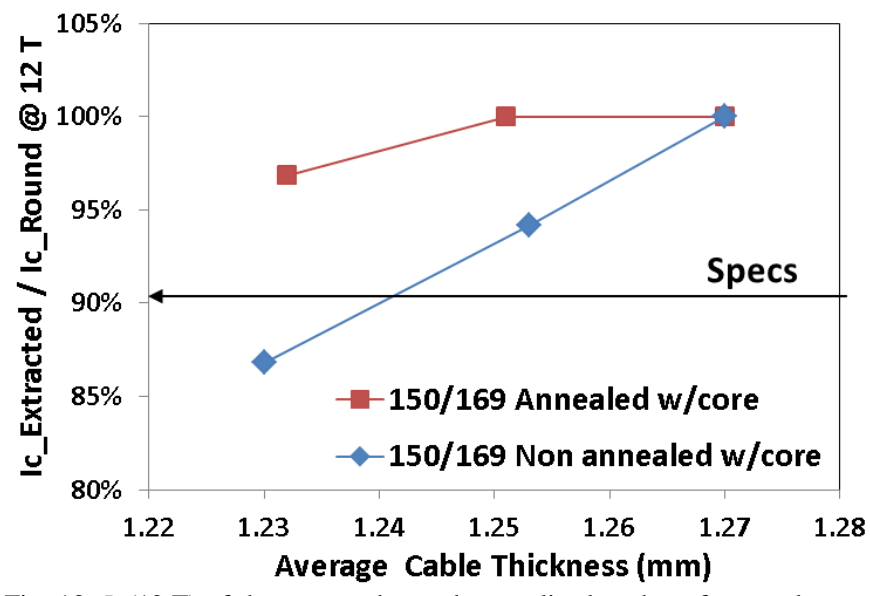

Fig. 13. $I_{c}(12 \mathrm{~T})$ of the extracted strand normalized to that of a round strand as function of cable mid-thickness for cable ID's 2 to 7 .

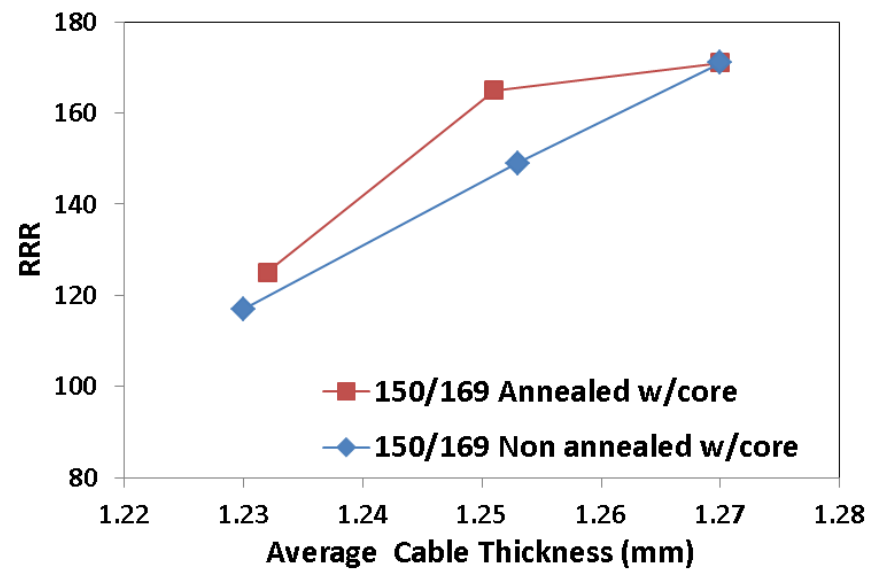

Fig. 14. RRR of the extracted strand as function of cable mid-thickness for cable ID's 2 to 7.

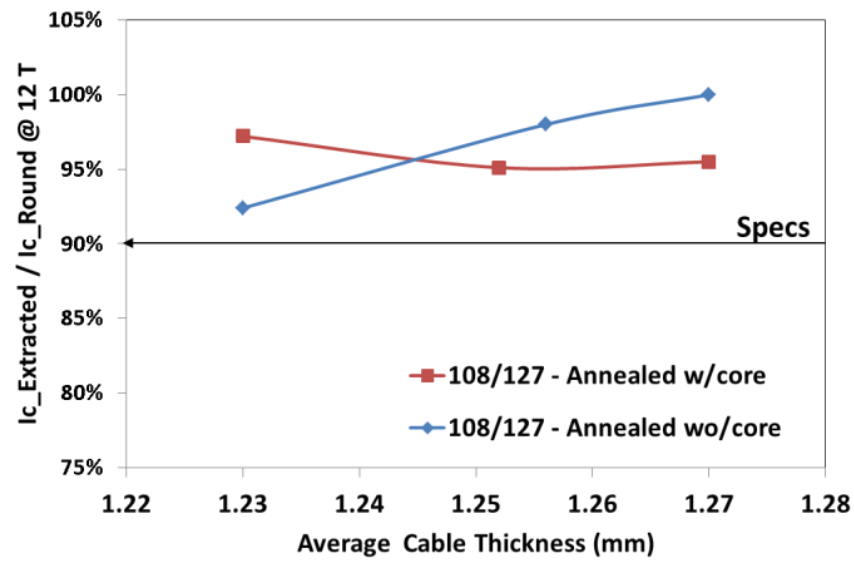

Fig. 15. $I_{c}(12 \mathrm{~T})$ of the extracted strand normalized to that of a round strand as function of cable mid-thickness for cable ID's 8 to 10, as compared with similar cables without a core from [3].

Figs. 16 and 17 compare the absolute $I_{c}(12 \mathrm{~T})$ and $R R R$ of the extracted strand as function of cable mid-thickness 
between cored cables made with RRP1 strands and cored cables made with RRP2 strands. These results confirm [11], where it was seen that the $I_{c}$ of the RRP1 wire degraded similarly under increasing flat-rolling deformation as that of RRP2, and showed $R R R$ values consistently larger.

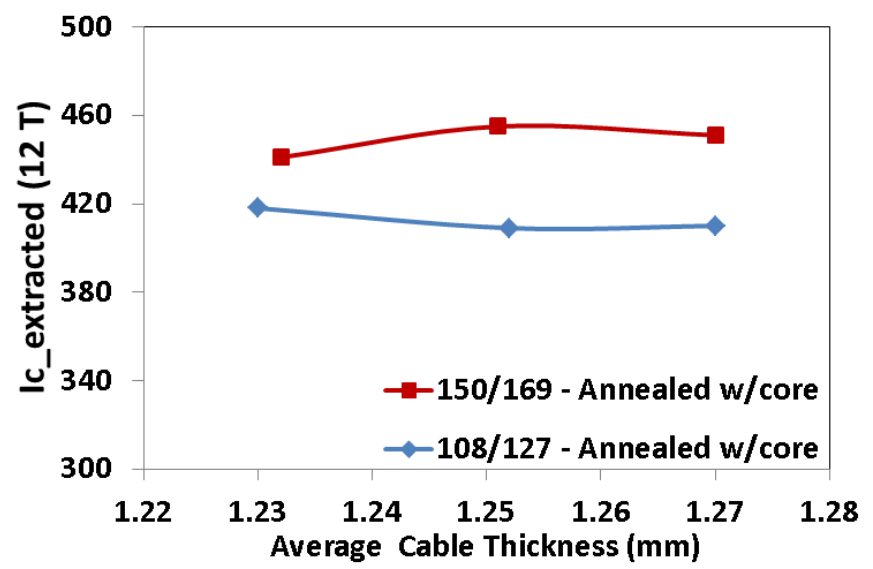

Fig. 16. $I_{c}(12 \mathrm{~T})$ of the extracted strand as function of cable mid-thickness for cable ID's 5 to 10 .

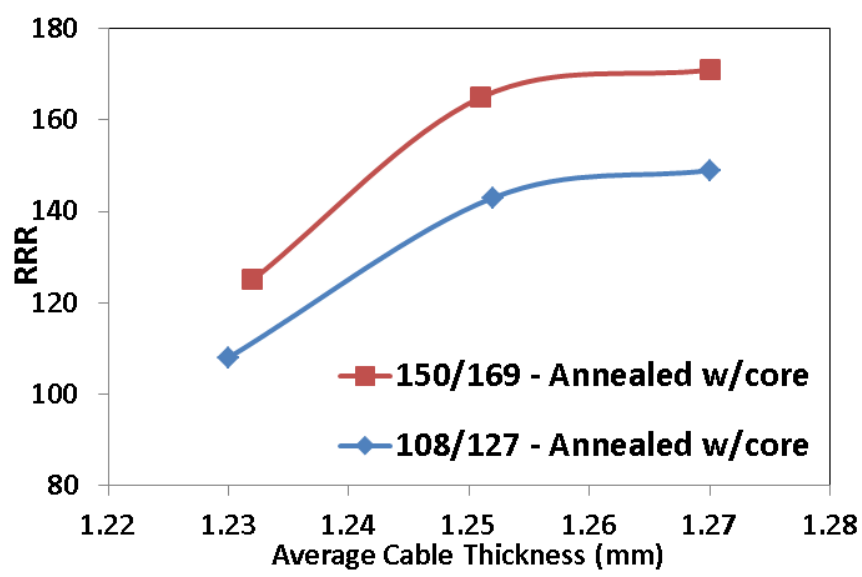

Fig. 17. RRR of the extracted strand as function of cable mid-thickness for cable ID's 5 to 10 .

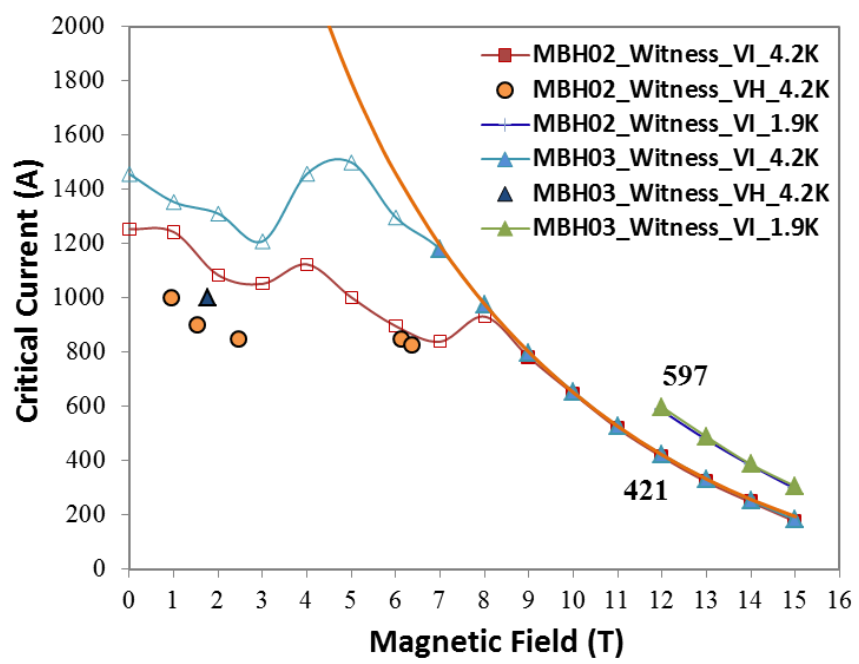

Fig. 18. $V-I$ and $V-H$ test results of extracted RRP2 wires used as witnesses of the demonstrator half-coils MBH02 and MBH03 [31].
To demonstrate in an actual coil such cored cable technology with this advanced strand, after manufacturing at FNAL of the $11 \mathrm{~T}$ demonstrator dipole MBHSP01 out of uncored cable made with the RRP2 baseline strand, a $1 \mathrm{~m}$ dipole model has been fabricated using $200 \mathrm{~m}$ of cored cable made with the RRP1 advanced wire [13]. This magnet has not been tested yet, but the transport behavior of RRP2 wires extracted from their cable and heat treated with the demonstrator half-coils $\mathrm{MBH} 02$ and $\mathrm{MBH} 03$ [31] can be compared with that of RRP1 wires extracted from their cable and heat treated with the $1 \mathrm{~m}$ long half-coil MBH05, i.e. as witnesses to their respective magnet reaction cycles. Once again we see a substantially better performance of the $150 / 169$ RRP®.

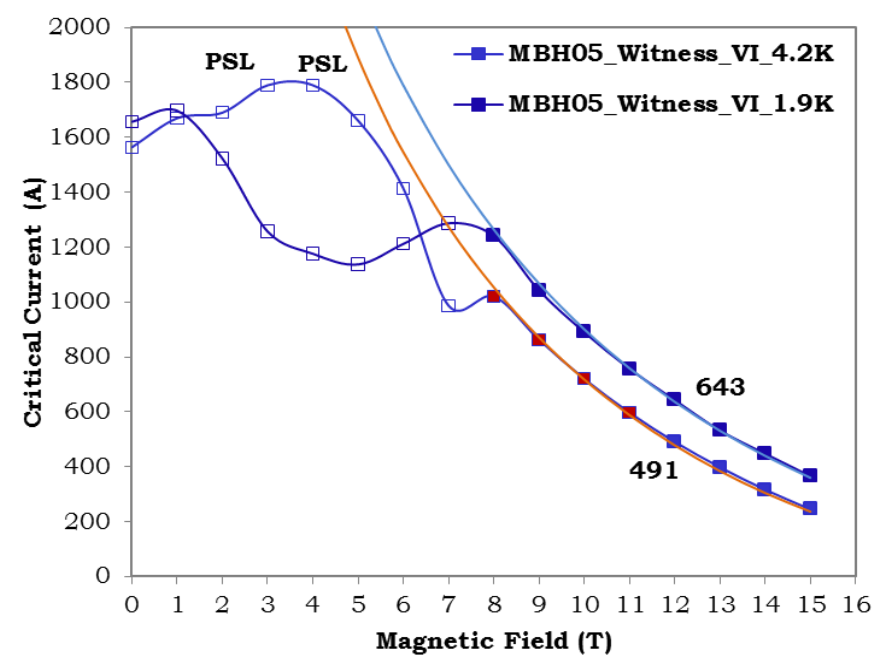

Fig. 19. $V-I$ and $V-H$ test results of extracted RRP1 wires used as witnesses of the demonstrator half-coil MBH05.

\section{B. Study of Cross-over Effects}

To start understanding the impact of cross-overs in $\mathrm{Nb}_{3} \mathrm{Sn}$ cables, a study was performed on RRP1 strands affected by a cross-over in cable ID 1 described in Table III. Fig. 20 illustrates a schematic of the cross-over layout in the cable. Strands No. 1 and No. 2 crossed at an edge (called "first damaged area" in the following) and re-crossed within the following half-pitch length ("second damaged area"). Strand No. 3 is that adjacent to strand No. 2, and strand No. 4 crosses the second damaged area in the cable from the cable back side. After extracting the affected strands from the cable, visual inspection identified strands No. 1 and No. 2 as the most damaged, with strand No. 3 coming next and strand No. 4 as being the strand with least visual damage. Pictures of all the seemingly damaged areas that were observed are shown in Figs. 21 to 23.

$V-I$ and $V-H$ measurements were then performed on these four strands, as well as on a fifth extracted strand that was located away from the cross-over areas, using the voltage scheme in Fig. 12. The $V-I$ test results for the five strands at 4.2 $\mathrm{K}$ are shown in Fig. 24 using voltage channel $\mathrm{CH} 5$. It is apparent that strands Nos. 1 and 2 are those electrically most affected. The quench location was determined to be $\mathrm{CH} 1$ for 
strand No. 1 and $\mathrm{CH} 2$ for strand No. 2. Figs. 25 and 26 show the $I_{c}(12 \mathrm{~T})$, and the stability current $I_{S}$ as measured through $\mathrm{V}-\mathrm{H}$ measurements for the five strands using voltage channel CH5. It is noticeable how even when the $I_{c}$ does not show any reduction, as in the case for instance of strand No. 3, the $I_{S}$ can suffer larger losses, confirming that it is a more sensitive indicator of damage than the $I_{c}[32]$.

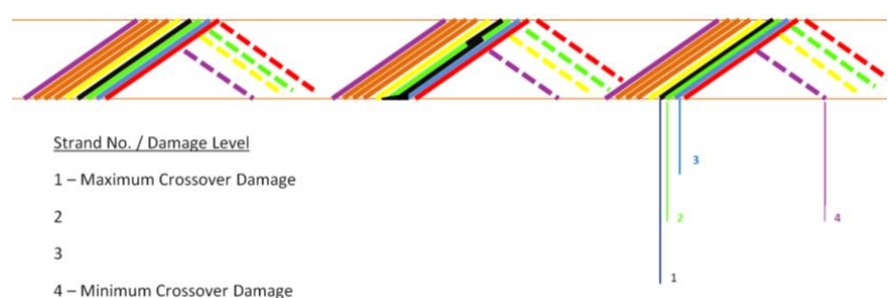

Fig. 20. Schematic of cross-over layout in cable ID 1. Strands No. 1 and No. 2 crossed at an edge and re-crossed within the following half-pitch length.

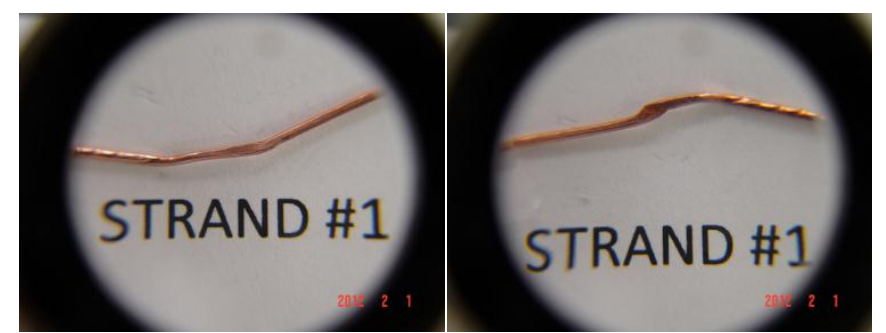

Fig. 21. Picture of first damaged area, which led to quench (left), and second damaged area (right) on strand No. 1.

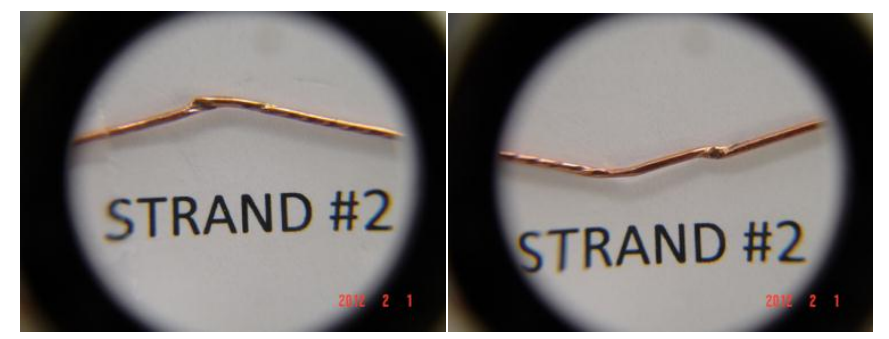

Fig. 22. Picture of first damaged area (left) and second damaged area, which led to quench (right), on strand No. 2.

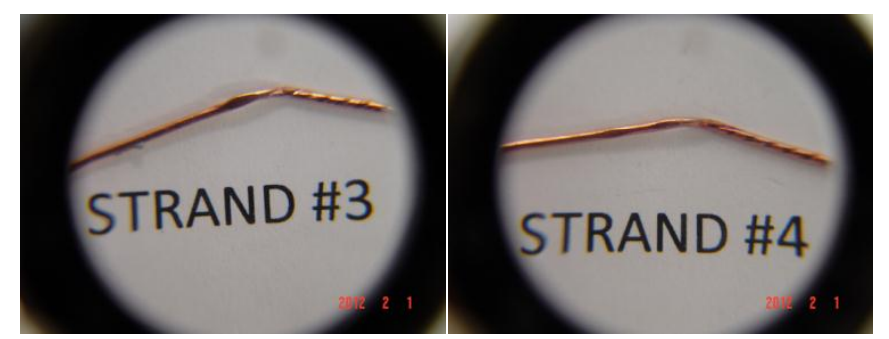

Fig. 23. Picture of area in strand No. 3 closest to first damaged area (left), and picture of area in strand No. 4 closest to second damaged area (right).

To investigate local $R R R$ reductions in the damaged areas of strands Nos. 1 and 2, following the $V-I$ and $V-H$ tests the samples were transferred onto G-10 barrels, and $R R R$ measurements were performed to compare their values across the two damaged areas with those across regular cable edges away from the cross-over. Figs. 27 and 28 show the results of these measurements for strand Nos. 1 and 2. As expected from Sn leaks in the affected areas, the local $R R R$ saw its largest reductions in the areas that developed a voltage first and led to quench in samples Nos. 1 and 2. However, there is no apparent correlation between the lowest $R R R$ values in each sample and their respective $I_{S}$.

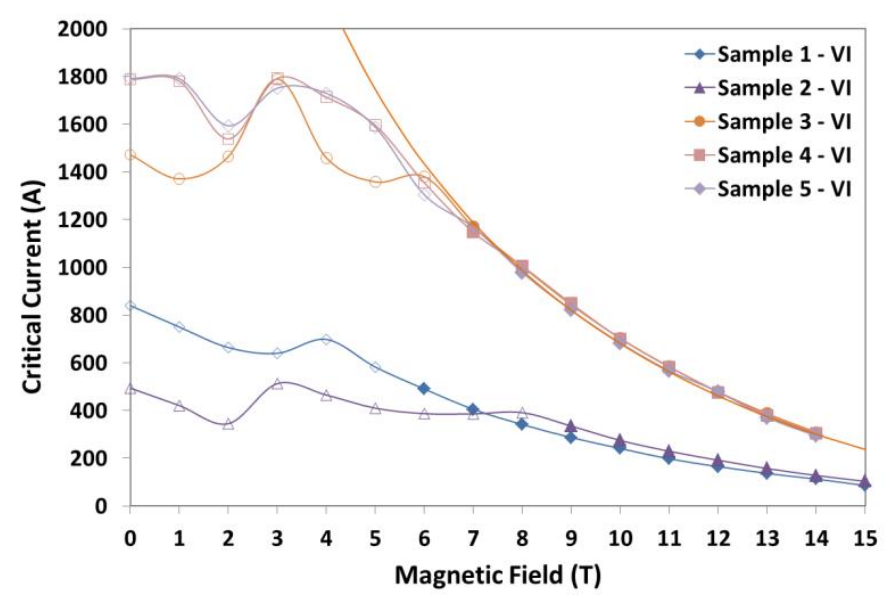

Fig. 24. $V-I$ test results at $4.2 \mathrm{~K}$ of strands Nos. 1 to 5 .

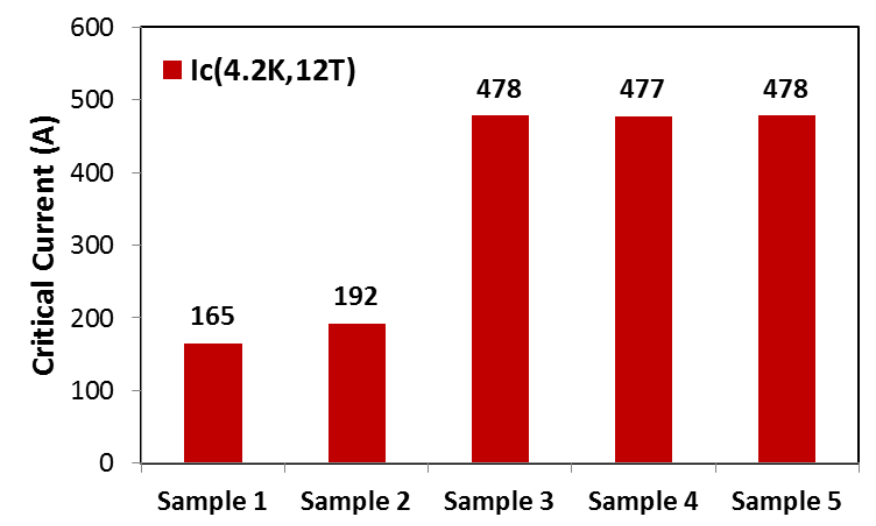

Fig. 25. $I_{c}(12 \mathrm{~T})$ at $4.2 \mathrm{~K}$ of strands Nos. 1 to 5.

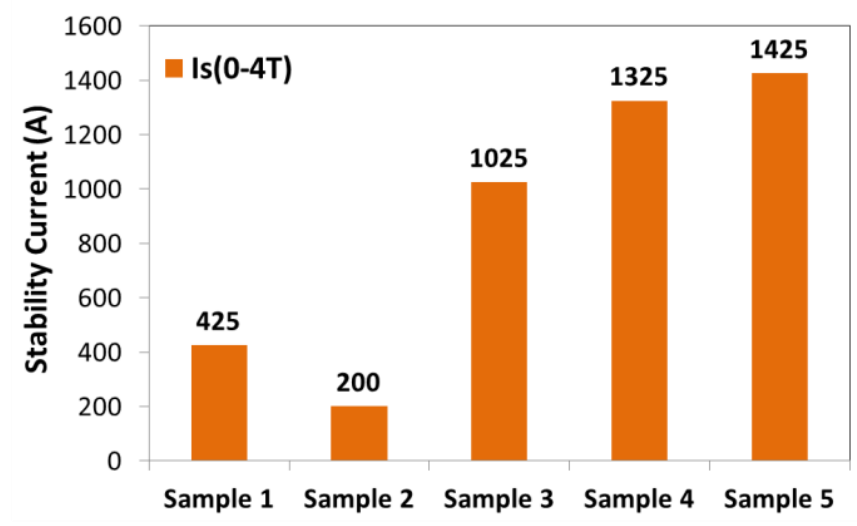

Fig. 26. $I_{S}$ at $4.2 \mathrm{~K}$ of strands Nos. 1 to 5.

The conclusion that can be drawn from this study is that a limited number of strands get affected by a cross-over, leading in principle to small overall reductions of current in the cable (3\% in this specific case). However, it is not at present clear whether voltage development in the affected area would lead to excessive heating and that the current would promptly redistribute before quenching the cable. This is the next aspect that needs investigation, possibly by means of a complete cable test that would take into account these combined factors. 


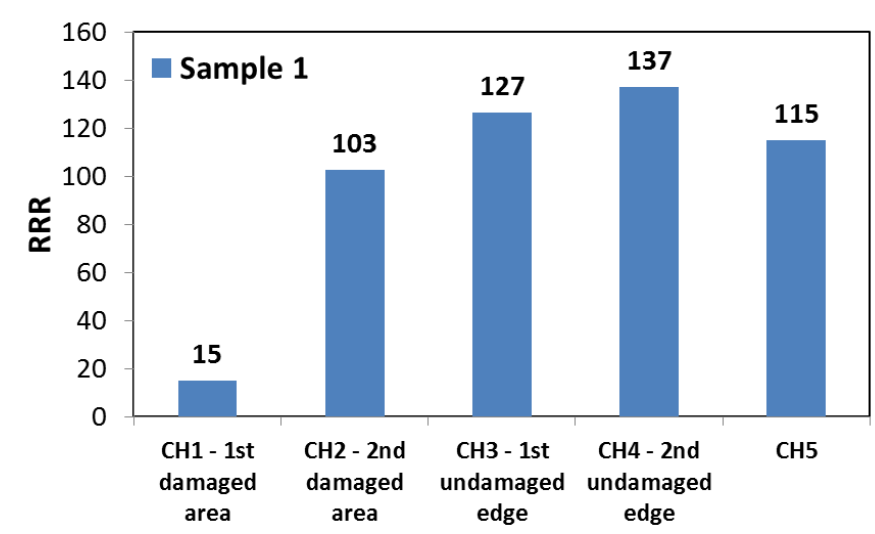

Fig. 27. Local $R R R$ measurements across the two damaged areas on strand 1, as compared with local $R R R$ measurements across adjacent cable edges away from the cross-over, and with the $R R R$ averaged along the full length of the sample.

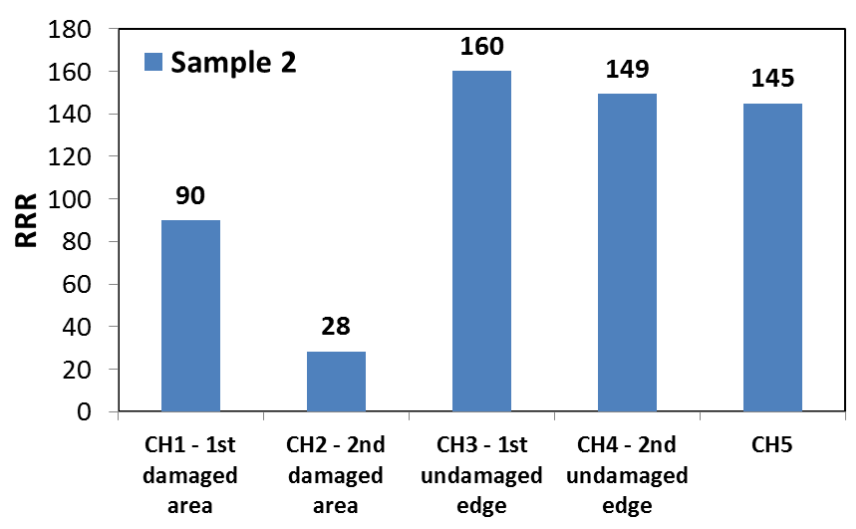

Fig. 28. Local $R R R$ measurements across the two damaged areas on strand 2, as compared with local $R R R$ measurements across adjacent cable edges away from the cross-over, and with the $R R R$ averaged along the full length of the sample.

\section{RESULTS FROM FEM STUDIES}

The study of $\mathrm{Nb}_{3} \mathrm{Sn}$ Rutherford-type cable manufacturing represents a challenging problem in physics and mechanical engineering. The process that conducts to the final cable geometry includes steps of high plastic deformation in order to produce the necessary cable compaction and mechanical stability. The problem is intrinsically non-linear, which makes it difficult to be solved analytically. Since the strands that compose the cable are initially made of elements $(\mathrm{Nb}, \mathrm{Sn}$ and $\mathrm{Cu}$ ) with very different mechanical properties, the problem is one of plastic deformation analysis of a composite material. The numerical simulation strategy that was chosen therefore accounts for an elevate number of contact elements, for friction and for large displacements.

After manufacturing, the cable needs to be thermally treated to obtain superconducting properties. Cables whose wires lose their integrity will lead to a worse superconducting performance after heat treatment. The purpose of mechanical analyses and experiments is to identify upper limits to plastic deformation to avoid irreversible damage, and to understand the influence of the various geometrical parameters in the process.

\section{A. FEM of Cable Manufacturing}

To obtain information on critical locations in the edge strands, in the original FEM model [33] the edge strands were modeled individually, by applying displacements obtained on a macro-model of the whole cable. In order to help convergence, the cable width and thickness compactions were applied in two subsequent load steps. This approach introduces an error, which becomes relevant for elevated values of plastic deformation, due to the non-linear behavior of the materials. Such model has now been improved and upgraded in a number of areas, as described in the following.

The full capabilities of Mechanical APDL (Ansys Parametric Design Language) are used to realize a number of key routines that automatically generate a cable geometry based on input parameters like number of strand $N$, strand diameter $d$, and lay angle $\psi$. The two-dimensional approximation, plane strain hypothesis and bi-linear isotropic material properties were all maintained. The detailed model for the edge strand is now immediately incorporated in the cable model, as shown in Fig. 29. Fig. 30 shows details of the mesh used at the edges. To recreate a realistic loading history, loads and displacements are ramped linearly and simultaneously. Springback was simulated by the choice of appropriate contact elements and friction values at the interface with the load and in between the strands. Unless otherwise specified, for the detailed model of the edge strand the RRP2 design was used.

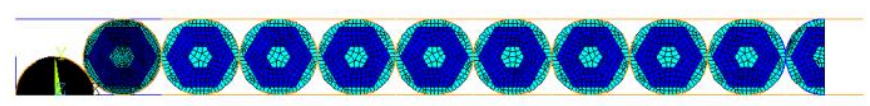

Fig. 29. Schematic of unloaded cable model.

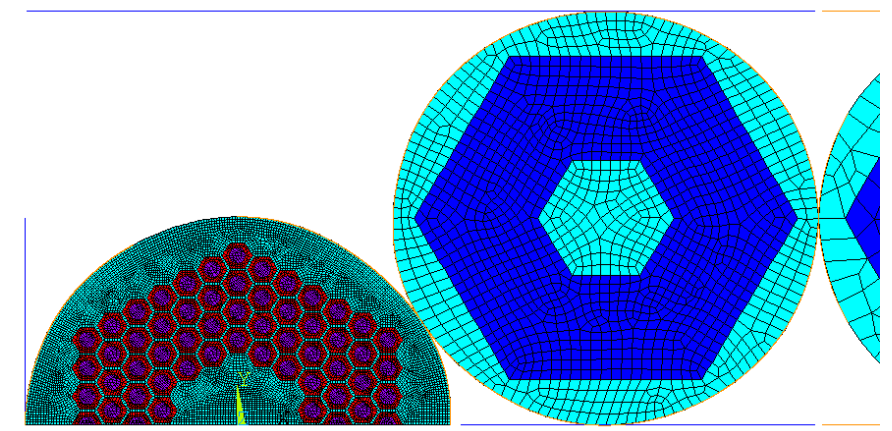

Fig. 30. Detail of mesh used at edges.

\section{B. Analysis of Strain Sensitivity to Width Compaction}

The study of the effects of width compaction $w_{c}=w i d t h_{\text {cable }} /$ width $_{\text {undeformed }}$ were performed for 40 -strand rectangular cables having $w_{c}$ values of 1.01, 0.99, 0.97 and 0.95 , and the same edge compaction $t_{c}=t_{\text {edge }} / 2 d=0.92$. As a good indicator of damage, the equivalent plastic strain distribution is shown in Fig. 31 for the edge strands. It was noted that the positive principal component of the strain tensor has a nearly identical distribution to that of the plastic strain. Following the strand map in Fig. 32, the equivalent plastic strain in the $\mathrm{Cu}$ channels exhibiting tensile stress is plotted in Fig. 33 as a function of 
channel location for the four width compaction values under study. These results show that in a cable the largest values of plastic deformation are generally located in the outermost part of the edge strand. These maximum values are plotted in Fig. 34 as function of $w_{c}$. However, these results show also that exceedingly compacting the cable in width produces a rapid increase in strain in the innermost part of the edge strand, as shown too in Fig. 34.

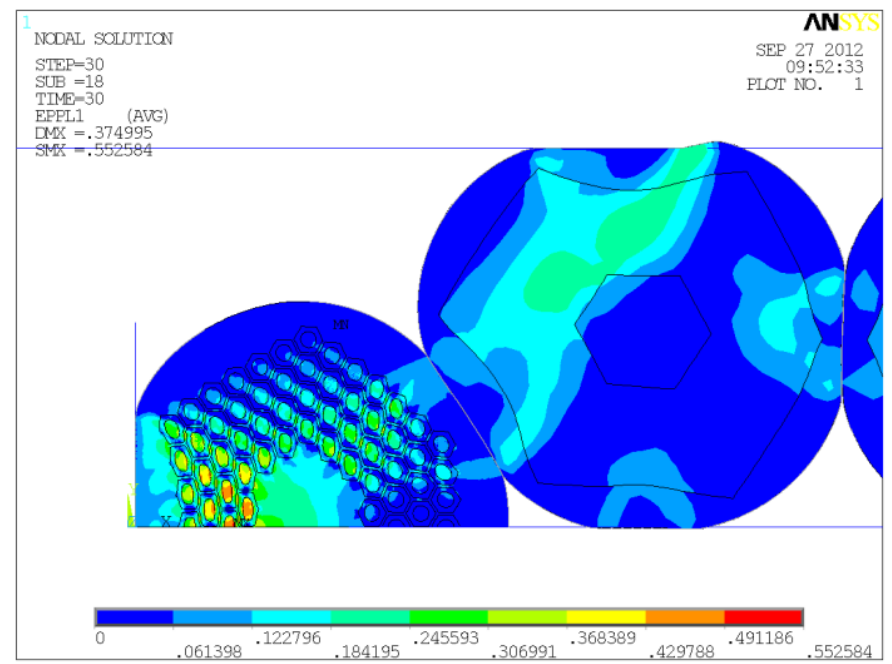

Fig. 31. Equivalent plastic strain at edge strands for a 40-strand rectangular cable having edge compaction $t_{c}$ of 0.92 and width compaction $w_{c}$ of 0.95 .

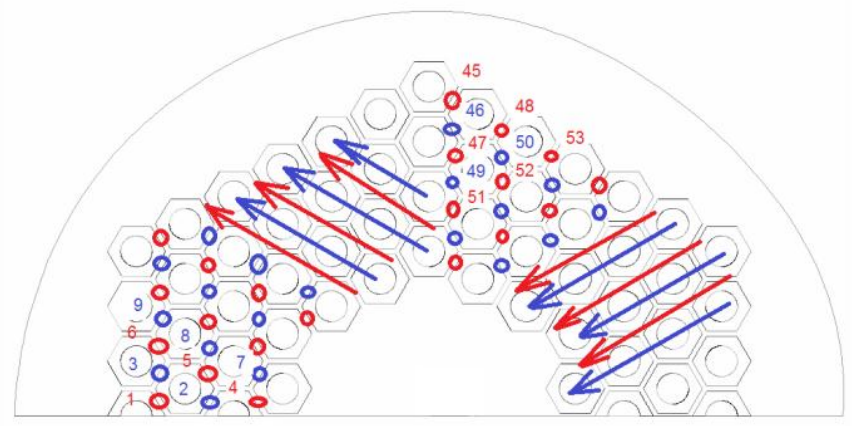

Fig. 32. Strain map identifying $\mathrm{Cu}$ channels exhibiting tensile stress, which is where fracture usually occurs. The numbering was chosen along diagonals where strain decreases monotonically from the innermost subelements toward the outer rows.

\section{Analysis of Strain Sensitivity to Keystone Angle}

Using the upgraded FEM model, an analysis of strain sensitivity to the keystone angle was performed for cables having keystone angles of $1.0 \mathrm{deg}$., $1.5 \mathrm{deg}$., and $2.0 \mathrm{deg}$., and same mid-thickness of $1.35 \mathrm{~mm}$ and width compaction $w_{c}$ of 1.01. The choice of appropriate contact elements was particularly relevant in this case to consistently predict that the maximum strain is always found in the strand adjacent to the edge strand, i.e. the maximum plastic strain is observed in the strand subjected to the maximum displacement. Figs. 35 to 37 show the equivalent plastic strain distribution in the three cables, and Fig. 38 summarizes the maximum equivalent plastic strain values as function of the cable keystone angle.

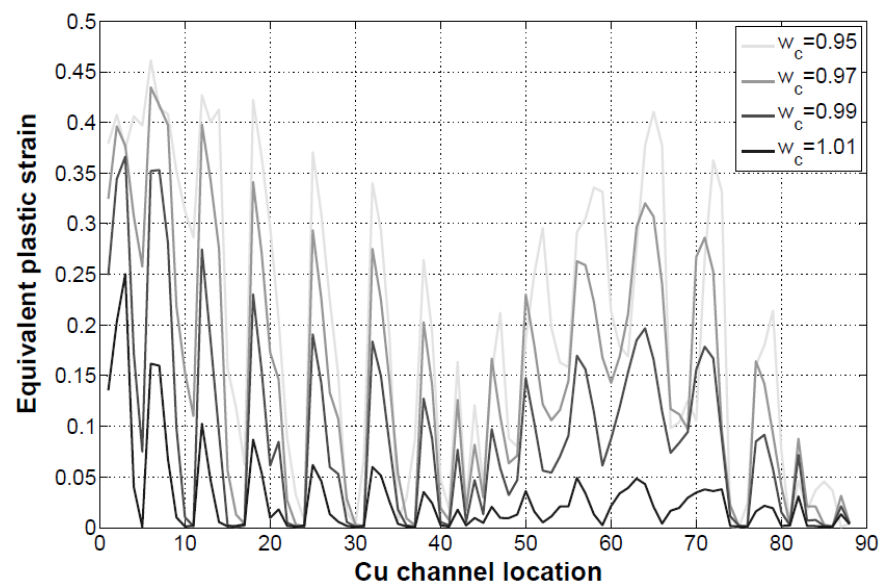

Fig. 33. Equivalent plastic strain in the $\mathrm{Cu}$ channels exhibiting tensile stress as a function of channel location according to map in Fig. 32 in edge strand of 40 -strand cables width compaction values of 1.01, 0.99, 0.97, and 0.95, and edge compaction of 0.92 . The largest value of strain corresponds to the smallest values of width compaction.

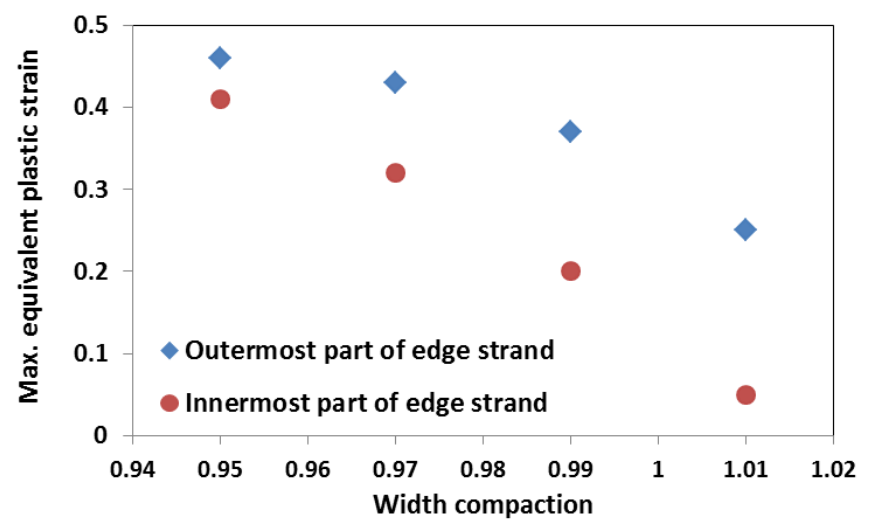

Fig. 34. Maximum equivalent plastic strain values in edge strand as function of cable width compaction for a 40-strand rectangular cable having edge compaction $t_{c}$ of 0.92 .

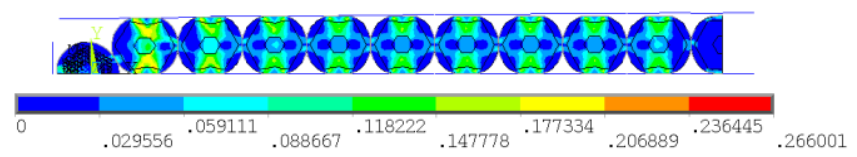

Fig. 35. Equivalent plastic strain distribution for 40-strand cable with $1.0 \mathrm{deg}$. of keystone angle, $1.35 \mathrm{~mm}$ of mid-thickness and width compaction $w_{c}$ of 1.01 .

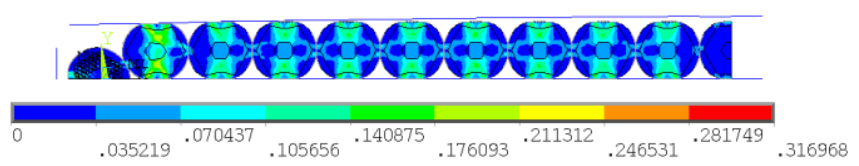

Fig. 36. Equivalent plastic strain distribution for 40 -strand cable with $1.5 \mathrm{deg}$. of keystone angle and $1.35 \mathrm{~mm}$ of mid-thickness and width compaction $w_{c}$ of 1.01 .

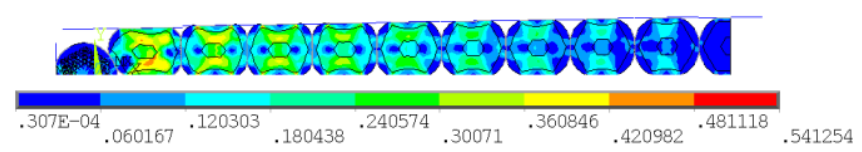

Fig. 37. Equivalent plastic strain distribution for 40 -strand cable with $2.0 \mathrm{deg}$. of keystone angle and $1.35 \mathrm{~mm}$ of mid-thickness and width compaction $w_{c}$ of 1.01 . 


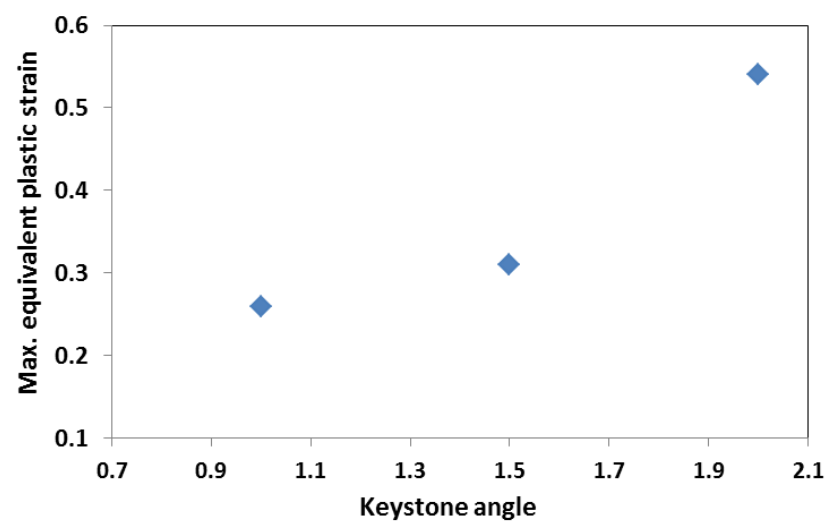

Fig. 38. Maximum equivalent plastic strain values in a cable cross section as function of its keystone angle for 40-strand cable with $1.35 \mathrm{~mm}$ of midthickness and width compaction $w_{c}$ of 1.01 .

\section{Modeling of a Core in the Cable}

Incorporating a $25 \mu \mathrm{m}$ thick stainless steel core in the model proved to be a challenging task. As can be observed experimentally (see for instance cross section picture in Fig. 11 ), the core assumes a wavy behavior, which is compatible with a non-linear buckling phenomenon. A typical example of such phenomenon is a beam subjected to high compressive loads, as in Fig. 39. The problem is complicated by the core material entering the plastic regime at some point during the deformation process. The addition of a core required also modifying the tangency condition of the strands in the geometrical pre-processing. And finally, the buckling leads to the loss of symmetry, requiring to double the size of cable section to be modeled. Equivalent plastic strain distributions are shown in Figs. 40 and 41 for a 40 -strand cable with a $0.025 \mu \mathrm{m}$ thick and $11 \mathrm{~mm}$ wide stainless steel core at its rectangular and keystoned stages. The rectangular stage was modeled with a thickness of $1.311 \mathrm{~mm}$ and width compaction of 0.99 , the keystoned stage was modeled with a keystone angle of 1.58 deg., a mid-thickness of $1.25 \mathrm{~mm}$, and width compaction of 1.01 .

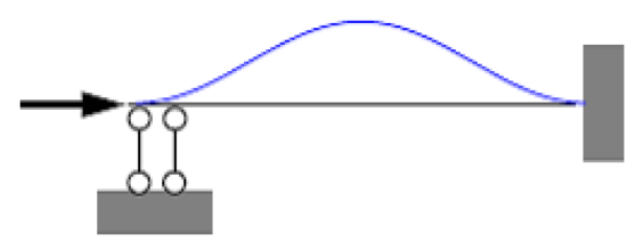

Fig. 39. Schematic of beam subjected to high compressive load, which can lead to buckling.

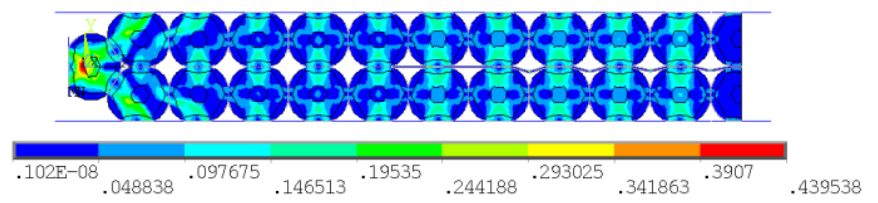

Fig. 40. Equivalent plastic strain distribution for 40 -strand rectangular cable $1.311 \mathrm{~mm}$ thick, with width compaction $w_{c}$ of 0.99 , and with a stainless steel core $0.025 \mu \mathrm{m}$ thick and $11 \mathrm{~mm}$ wide.

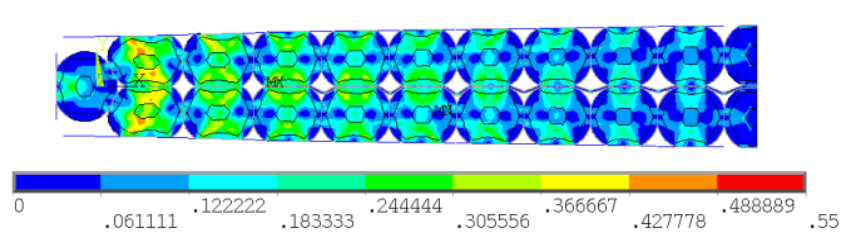

Fig. 41. Equivalent plastic strain distribution for 40-strand cable with keystone angle of 1.58 deg., $1.25 \mathrm{~mm}$ mid-thickness, width compaction $w_{c}$ of 1.01, and with a stainless steel core $0.025 \mu \mathrm{m}$ thick and $11 \mathrm{~mm}$ wide.

\section{CONCLUSION}

To investigate conductors suited for high field magnet applications, a larger Superconducting Strand and Cable R\&D lab was established at FNAL's Technical Division. This is an ideal experimental environment for graduate students and postdocs to train in performing research.

The 108/127 RRP® [11], which is presently a baseline conductor in the U.S. for $\mathrm{Nb}_{3} \mathrm{Sn}$ magnet R\&D, has proven to provide acceptable performance in magnets, albeit with little margin for error [4, 6]. A more advanced 150/169 RRP® strand, with better $I_{c}$, better $R R R$ and lower subelement size [13], was used in cabling studies and its behavior in cables compared with that of the baseline wire. These studies have confirmed that the $150 / 169$ is competitive also when used in cables.

A cored cable technology was developed and studied. The cabling studies showed that a mid-thickness specification of $1.25 \mathrm{~mm}$ for the $11 \mathrm{~T}$ dipole cable meets the $I_{c}$ degradation requirements also in the case of a cored cable made with either RRP1 or RRP2 wire. Using the same cable geometry for cored and uncored cable allows preserving the same insulation thickness in a magnet.

To demonstrate in an actual coil such cored cable technology with the advanced RRP1 strand, a $1 \mathrm{~m}$ dipole model has been fabricated using $\sim 200 \mathrm{~m}$ of cored cable made with this wire [13]. This magnet will be tested soon, and its test results may have impact on future conductor choices for the $11 \mathrm{~T}$ Dipole program and other $\mathrm{Nb}_{3} \mathrm{Sn}$ programs.

A study to determine the effect of cross-overs in $\mathrm{Nb}_{3} \mathrm{Sn}$ cables was performed on RRP1 strands affected by a crossover in a 40-strand rectangular cable. The conclusion that was drawn from this study is that a limited number of strands get affected by a cross-over, leading in principle to small overall reductions of current in the cable. However, more needs to be understood on whether voltage development in the affected area would lead to heating sufficient to quench the cable. The next step is an actual cable test.

A finite element model was upgraded to better represent the actual cable manufacturing process. The model was then used to study strain sensitivity to cable width compaction and to keystone angle. Finally, a model was successfully made of the behavior of a thin stainless steel core in a Rutherford cable. 


\section{ACKNOWLEDGMENT}

E. Barzi is grateful to her group's members Allen Rusy, Tom VanRaes, and Marianne Bossert for their competence, creative initiative, and long standing dedication to our common mission.

\section{REFERENCES}

[1] A.V. Zlobin, G. Apollinari, N. Andreev, E. Barzi, V.V. Kashikhin, F. Nobrega, I. Novitski, B. Auchmann, M. Karppinen, and L. Rossi, "Development of $\mathrm{Nb}_{3} \mathrm{Sn} 11 \mathrm{~T}$ single aperture demonstrator Dipole for LHC Upgrades", Proceedings of the $24^{\text {th }}$ Particle Accelerator Conference (PAC 2011), March 28 - April 1, 2011, New York, USA.

[2] E. Barzi et al., " $\mathrm{Nb}_{3}$ Sn Cable Development for the $11 \mathrm{~T}$ DS Dipole Demonstration Model", AIP (2012).

[3] E. Barzi, N. Andreev, M. Karppinen, V. Lombardo, F. Nobrega, D. Turrioni, R. Yamada, and A.V. Zlobin, "Development and Fabrication of $\mathrm{Nb}_{3} \mathrm{Sn}$ Rutherford Cable for the $11 \mathrm{~T}$ DS Dipole Demonstration Model”, IEEE Trans. Appl. Sup., Vol. 22, Issue 3, June 2012.

[4] H. Felice et al., "Test results of TQS03: a LARP shell-based $\mathrm{Nb}_{3} \mathrm{Sn}$ quadrupole using 108/127 conductor", H. Felice et al., $9^{\text {th }}$ European Conference on Applied Superconductivity (EUCAS 2009), Sep. 13-17, 2009, Dresden, Germany.

[5] G. Ambosio et al., "Progress in the Long $\mathrm{Nb}_{3} \mathrm{Sn}$ Quadrupole $\mathrm{R} \& \mathrm{D}$ by LARP", accepted in IEEE.

[6] A. Zlobin et al., "Testing of $\mathrm{Nb}_{3} \mathrm{Sn}$ quadrupole coils using magnetic mirror structure", Advances in Cryogenic Engineering, V. 55, AIP, V. 1218, pp. 1031-1038 (2010).

[7] R. Bossert et al., "Fabrication and Test of 4-m Long $\mathrm{Nb}_{3} \mathrm{Sn}$ Quadrupole Coil Made of RRP-114/127 Strand", accepted in AIP.

[8] L. Rossi et al., "Advanced Accelerator Magnets for Upgrading the LHC", $M T-22$.

[9] M. Karppinen et al., "Design of $11 \mathrm{~T}$ Twin-Aperture $\mathrm{Nb}_{3} \mathrm{Sn}$ Dipole Demonstrator Magnet for LHC upgrades", IEEE Trans. Appl. Sup., Vol. 22, Issue 3, June 2012.

[10] G. de Rijk, A. Milanese, E. Todesco, "11 Tesla $\mathrm{Nb}_{3}$ Sn dipoles for phase II collimation in the Large Hadron Collider", sLHC Project Note 0019, 2010.

[11] M. B. Field et al., "Internal tin $\mathrm{Nb}_{3} \mathrm{Sn}$ conductors for particle accelerator and fusion applications", Advances in Cryogenic Engineering, vol. 54, pp. 237-243 (2008).

[12] E. Barzi et al., "Development and study of $\mathrm{Nb}_{3} \mathrm{Sn}$ strands and cables for high field accelerator magnets", Advances in Cryogenic Engineering, V. 56, AIP, V. 1219, pp. 183-190 (2010).

[13] E. Barzi, M. Bossert, G. Gallo, V. Lombardo, D. Turrioni, R. Yamada, and A.V. Zlobin, "Studies of $\mathrm{Nb}_{3}$ Sn Strands based on the Restacked-Rod Process for High-field Accelerator Magnets", IEEE Trans. Appl. Sup., Vol. 22, Issue 3, June 2012.

[14] Luc Oberli, CERN, private communication.

[15] N. Andreev et al., "Development of Rutherford-type Cables for High Field Accelerator Magnets at Fermilab", IEEE Trans. Appl. Sup., V. 17, No. 2, p. 1027 (2007).

[16] E. Barzi, D. Turrioni, A. Kikuchi, M. Lamm, A. Rusy, R. Yamada, and A. V. Zlobin. "BSCCO-2212 Wire and Cable Studies", Advances in Cryogenic Engineering, V. 54, AIP, V. 986, p. 431-438 (2008).

[17] A. Kikuchi, R. Yamada, K. Tsuchiya, T. Nakamoto, E. Barzi, D. Turrioni, K. Sasaki, Q. Xu, A. Terashima, H. Takigawa, A. Yamamoto, K. Nakagawa, T. Takeuchi, M. Lamm, and A. V. Zlobin. "Strand and Cable Development for a High Field $\mathrm{Nb}_{3} \mathrm{Al}$ Common Coil Magnet", IEEE Trans. Appl. Sup., V. 20, No. 3, p. 1428 (2010).

[18] E. Barzi et al., "Effect of Temperature and Deformation on $\mathrm{Nb}_{3} \mathrm{Sn}$ Strands Instabilities", Advances in Cryogenic Engineering, V. 52, AIP, V. 824, pp. 566-574 (2006).

[19] E. Barzi, V. Lombardo, A. Tollestrup, D. Turrioni, "Study of Effects of Transverse Deformation in BSCCO-2122 Wires", IEEE Trans. Appl. Sup., V. 21, No. 3, p. 2808 (2011).

[20] D. Turrioni, E. Barzi, M. Lamm, V. Lombardo, C. Thieme, and A. V. Zlobin. "Angular Measurements of HTS Critical Current for High Field", SolenoidsAdvances in Cryogenic Engineering, V. 54, AIP, V. 986, pp. 451-458 (2008).

[21] D. Turrioni, E. Barzi, M. J. Lamm, R. Yamada, A.V. Zlobin, and A. Kikuchi, "Study of HTS Wires at High Magnetic Fields", IEEE Trans. Appl. Sup., V. 19, No. 3, p. 3057 (2009).
[22] E. Barzi, D. Turrioni, and A. V. Zlobin, "Effect of Transverse Pressure on Brittle Superconductors", IEEE Trans. Appl. Sup., V. 18, No. 2, p. 980 (2008).

[23] E. Barzi, N. Dhanaraj, V. Lombardo, and D. Turrioni, "Design of a Probe for Strain Sensitivity Studies of Critical Current Densities in Superconducting Wires", IEEE Trans. Appl. Sup., V. 20, No. 3, p. 1626 (2010).

[24] E. Barzi, N. Andreev, V. V. Kashikhin, D. Turrioni, and A. V. Zlobin, "Study of $\mathrm{Nb}_{3} \mathrm{Sn}$ Cable Stability at Self-field using a Superconducting Transformer", IEEE Trans. Appl. Sup., V. 15, No. 2, p. 1537 (2005).

[25] N. Andreev et al.. "Superconducting Current Transformer for Testing $\mathrm{Nb}_{3} \mathrm{Sn}$ Cable Splicing Technique", IEEE Trans. Appl. Sup., V. 13, No. 2, p. 1274 (2003).

[26] E. Barzi, N. Andreev, J. Brandt, C. Carmignani, M. Danuso, V. V. Kashikhin, V. S. Kashikhin, S. Mintchev, D. Mitchell, D. Turrioni, A. Rusy, and A. V. Zlobin, "Superconducting Transformer for Superconducting Cable Tests in a Magnetic Field", Advances in Cryogenic Engineering, V. 55, AIP, V. 1218, pp. 421-428 (2010).

[27] V. Lombardo, A. Bartalesi, E. Barzi, M. Lamm, D. Turrioni and A. V. Zlobin, "Modular Test Facility for HTS Insert Coils", IEEE Trans. Appl. Sup., V. 20, No. 3, p. 587 (2010).

[28] V. Lombardo, E. Barzi, D. Turrioni and A. V. Zlobin, "Insert Coil Test for HEP High Field Magnets using $\mathrm{YBa} 2 \mathrm{Cu} 3 \mathrm{O} 7-\delta$ Coated Conductor Tapes", AIP (2012).

[29] E. W. Collings et al.. "Influence of a Stainless Steel Core on Coupling Loss, Interstrand Contact Resistance, and Magnetization of an $\mathrm{Nb}_{3} \mathrm{Sn}$ Rutherford Cable", IEEE Trans. Appl. Sup., V. 18, No. 2, p. 1301 (2008).

[30] E. W. Collings et al., "Coupling- and Persistent-Current Magnetizations of $\mathrm{Nb}_{3} \mathrm{Sn}$ Rutherford Cables", E. W. Collings, M. D. Sumption, M. A. Susner, E. Barzi, D. Turrioni, R. Yamada, A. V. Zlobin, and A. Nijhuis. IEEE Trans. Appl. Sup., V. 20, No. 3, p. 1387 (2010).

[31] A.V. Zlobin, N. Andreev, G. Apollinari, E. Barzi, R. Bossert, G. Chlachidze, V.V. Kashikhin, A. Nobrega, I. Novitski, D. Turrioni, R. Yamada, B. Auchmann, M. Karppinen, L. Oberli, L. Rossi, and D. Smekens, "Status of a Single-Aperture $11 \mathrm{~T} \mathrm{Nb}_{3} \mathrm{Sn}$ Demonstrator Dipole for LHC Upgrades", Proceedings of the International Particle Accelerator Conference 2012 (IPAC12), May 20-25, 2012, New Orleans, Louisiana, USA.

[32] E. Barzi et al., "RRP $\mathrm{Nb}_{3} \mathrm{Sn}$ Strand Studies for LARP", IEEE Trans. Appl. Sup., V. 17, No. 2, p. 2607 (2007).

[33] Emanuela Barzi, Giuseppe Gallo, and Paolo Neri, "FEM Analysis of Nb-Sn Rutherford-type Cables", IEEE Trans. Appl. Sup., Vol. 22, Issue 3, June 2012. 